\title{
Familial Hemiplegic Migraine
}

National Cancer Institute

\section{Source}

National Cancer Institute. Familial Hemiplegic Migraine. NCI Thesaurus. Code C117009.

A mig raine disorder characterized by individual and family history of aura that includes motor weakness. 